\title{
Exhibition Design Affordance to Provide New Visitor's Experience in Museum Ullen Sentalu Yogyakarta
}

\author{
Arwin Purnama Jati \\ Visual Communication Design \\ Soegijapranata Catholic University \\ Semarang, Indonesia \\ arwinpj@gmail.com, arwin@unika.ac.id
}

\author{
Bayu Widiantoro \\ Visual Communication Design \\ Soegijapranata Catholic University \\ Semarang, Indonesia widiantoro@unika.ac.id
}

\begin{abstract}
Ullen Sentalu Museum (USM) in Yogyakarta has a specific concept of layout spaceas it is built in a natural reserve area in Kaliurang Yogyakarta. The blend of natural nuance and the concept of Javanese cultural history and hybrid architecture become the highlight of the museum. The space design and the artifacts display were studied to see its influence on visitor experience. Observation is held to observe the flow of the visits and to classify the exhibition design of the museum. The USM provides interior and exterior exhibition space in the diverse area to display the artifacts. The exhibition design in the USM can provide a repertoire in the discourse of the museum through the design of space and area, the concept of display, and the mechanism of museum visits. The exhibition design through the design of space is afford to provide the new experience of visitors.

Keywords - exhibition design, museum, visitor experience, architecture, space
\end{abstract}

\section{INTRODUCTION}

In this article, we discuss the exhibition design at the Ullen Sentalu Museum (USM) Yogyakarta. The selection of this Javanese art and culture museum is based on the uniqueness of museum location, which is located in a natural conservation area of Kaliurang Yogyakarta. Artifact displays as identification of a museum is placed in various areas in the museum. Various forms of display placement, arrangement of artifacts, and the architectural design, as well as nature surrounding become a highlight for MUS as tourist's favorite museum.

The museum, titled "Museum of Art and Culture", exhibits historical artifacts which are Javanese cultural heritage. The museum was founded by Haryono family who received an appreciation and support from Kraton Yogyakarta (Yogyakarta Palace) for their contribution to the cultural conservation through USM. The Javanese concept is designed for most USM buildings and it is built to show visitors about past culture that called as "mnemonic". The USM buildings and spaces concept might attract visitor to explore entire space in this museum as well as the exhibition.

The exhibition design factor became the main focus of this research. Observations on location were conducted to see how the USM design space provided new experiences for tourists. In the perspective of museology, USM is considered an implementation of a "new museology" based on the mechanism of tour service educators to support museum visits (Haryono, 2011). The mechanism is said to enhance the information gaining when visitors observing artifacts, as the information will be explained by the educator tour during the visit. The space factor in the previous study of Henri Lefebvre (2011) became a way to determine the pattern of visitor behavior in space. Space, through its design might affect people to act or behave in a space. Space also influences people's thought when a person in the space. A person's experience of visiting a museum will meet new experience when entering a museum with new nuances. The exhibition design of the USM museum is considered as unique related to the spatial arrangement, so that visitors get extra experience of enjoying artifacts while at the same time enjoying the natural nuances that surround the USM space.

This article contains several contributions, including:

1. Description of the museum space design that serves as an exhibition space for artifacts. The exhibition design displayed as a space is explored and described by its shape, size and architecture style. Different forms of space in the USM exhibition raise visitor insights about museum space.

2. Identification of spaces in museum exhibition designs that influence visitor's action in a space when enjoying object displayed. Tour visits in USM spaces with diverse design make visitors enjoy space in different ways.

The conclusion of this article is a discussion about the function of space. The function is not only conventional or single function, but can also have additional functions that provide new experiences for museum visitors. Exhibition design becomes such an exploration that gives value to its visitors. This means that objects or artifacts in the museum are not the only elements that build a museum exhibition. The museum display space can be identified as other 'artifact' elements enjoyed by the visitors. USM buildings through collections and object displays manifest as museum identities that have meaningful symbolic aspects. Regarding contemporary architecture, Sirefman (1999) mentions that architecture is a narrative metaphor for social construction.

\section{METHODS}

This study was carried out by visiting and observing USM spaces. The visit was carried out by following the tour to the entire museum space in a visiting program with a tour educator. Observations are carried out by observing spaces directly and taking example of several spaces that represent various types of space forms or artifact display space. Visit spaces were observed in terms of shape and size, as well as the placement in the museum area. Observation is also done by observing the patterns of visitor's visits in USM space, such as how visitors enjoy space or artifacts, how to enter or pass through the museum room, and so on. The context of space, area, and 
the way visitors explore the space becomes the main context in observation.

Literature data is also used as method to guide, support, and assess the suitability between data in the form of observable facts obtained through observation with existing theories. For the record, MUS's general data is partly obtained / quoted from the research literature on the previous MUS. While most of the field data is obtained through gradual and closed field observations (covert observation).

There are two main part of observation of USM, which are display space/ room and the reaction of visitors. The observation result is analyzed and studied with literature data support.

\section{A. Display space/ room}

Display space observed including interior and exterior exhibition space. There are several models of display space in USM. For example, the artifacts are displayed in hall, hallway, underground passageways, and open areas with garden.

Hall

Hall-shaped rooms are basically used to display artifacts that have large dimensions, such as sculptures and musical instruments. There are also spaces with artifacts placed in a glass display space and not displayed in the middle of the room. In this space, visitors observe artifacts by walking along the walls where the glass display spaces are located. The hall-shaped room is especially ease visitors to move or gather around with the tour educator to listen the explanations about artifacts.

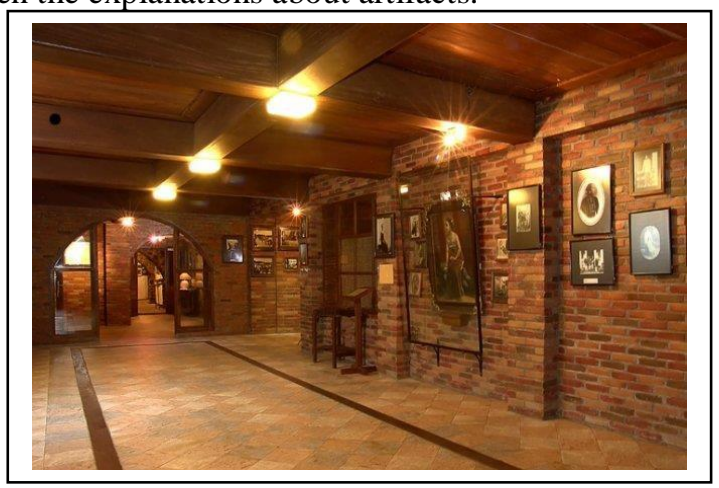

Figure 1. Hall "Gua Selo Giri"

(Source: javabackpacker.blogspot.com)

The hallway

The USM hallway is mainly built to connect one to another display spaces. In the hallway, a number of statues or three-dimensional decorations are displayed. The elongated shape of the hallway allows visitors to simply pass while walking and not stop by in the hallway too long.

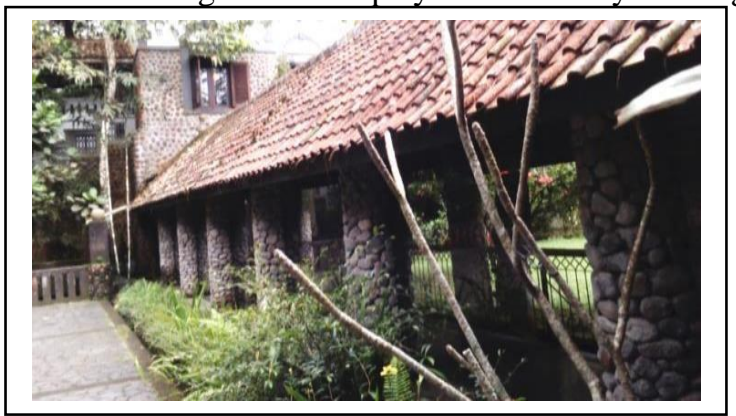

Figure 2. Hallway Retja Landa (Source: private collection)
Underground hallway

The underground hallway-shaped at USM is located in the initial room of the visit. It can be said as the gateway to the first display room (permanent showroom) of the tour. The hallway that is located underground insists visitors to walk one by one because of the elongated shape of the aisle. Narrow aisles also limit visitor's moves as they are not easy to walk side by side with the other. This affects the visitor interaction with other visitors, for example, the visitor mostly only have a little talk with the other while passing the hallway. Additionally, visitors tend not to stop walking while in the hallway as they have to provide walking space for other visitors who walk behind them.

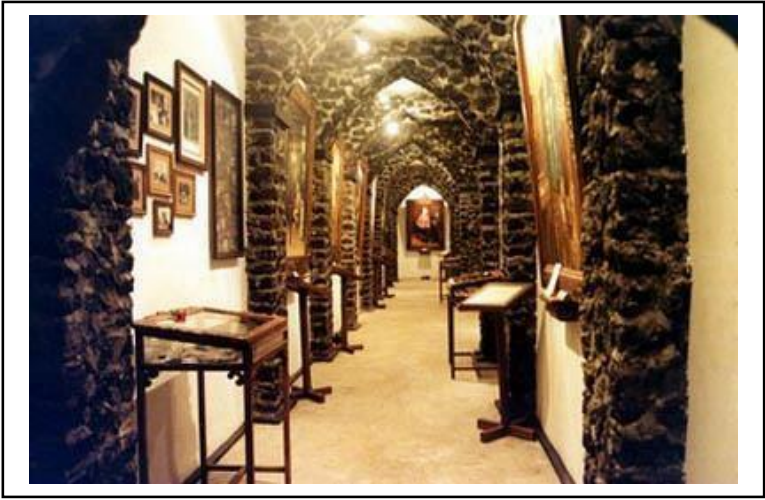

Figure 3. Underground hallway "Gua Selo Giri" (Source: tourjogja.com)

Garden area

The park or garden area is the most extensive and open area. Visitors tend to move freely in this area. In this area visitors also make it possible to walk with their own walking rhythms, quickly or slowly. This area allows visitors to relax while enjoying the open air and garden atmosphere.

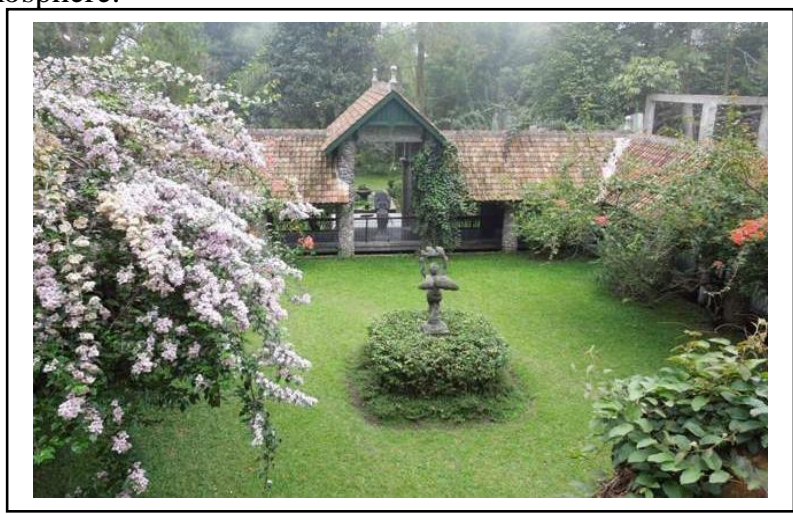

Figure 4. Garden area in the middle of hallway "Retja Landa" (Source: blognyamitra.wordpress.com)

\section{B. Reaction of visitors}

In observation, there were also observations about visitors when enjoying artifact displays or when in space. Some visitors move or walk by adjusting the shape or size of space. For example, when walking in a hall-shaped room, visitors look relaxed moving, with different walking rhythms. Meanwhile, when walking down the hall or the hallway, visitors tend to be quiet and focus on their respective movements, and walk faster because they follow the direction of the tour educator who leads the visitors as a navigator. The visitor reaction is mainly seen through their comments or talks as they move from one 
place to another. Visitors tend to comment or observe the room they have just visited. Forms or layouts of space they visit recently that are different from previous space may be an indicator of visitors' comments.

\section{RESULTS}

The findings from observations in USM indicate that USM space affects how visitors move and react. Space with different shapes and dimensions makes visitors react differently as well. This brings out insight to visitors in the way of visiting museum with a different space design or layout design. The experience of visitors when visiting a museum that is previously conventional is compared with their experience visiting USM. USM's space design and its hybrid architecture provide a new perspective in the way museum exhibit its artifacts. The combination of the interior and the natural exterior as an artifact display space gives a new nuance in the design of the museum exhibition. Various architectural styles, space design concepts, and tour educator mechanisms also enrich USM's image as an unconventional museum.

In addition to the diverse space design that builds USM's image, USM space design contributes and triggers the actions of visitors. Visitor actions such as moving, walking, and interacting with other visitors are influenced by the shape and dimensions of the space where the visitors are. The design of the space is an indicator of the movement of visitors and interaction between visitors. Visitors mainly interact with buildings in the MUS environment, especially in the space. This interaction, for example; the way visitors walk, climb stairs, walk down the aisle, touch the objects or artifacts, and so on. Through interaction or contact with artifacts, there is construction in a way that stores meaning (Davis, 1995). These methods, for example, an installation that is placed adjusting to the visitor's space, that is, the placement of objects in the area where the visitor passes, the distance of objects are placed, and so on.

Visitor insights of visiting a museum with general exhibition space design are added with their new experiences of visiting USM. Especially as it related to the context of displaying artifact in museum built with hybrid architecture, interior and exterior display area combined with natural nuances. It can be considered as museum exploration for the visitors. As it said by Maranda and Soares (2017) that through museum display (of objects) and its cultural interpretation together with the materials, museum is perceived as exploration and learning place for most people.

\section{CONCLUSION}

The conclusions obtained through the design study of USM exhibition are based on the findings through observation. The study of museum exhibition design is also not a new study. However, some findings indicate that different architectural styles or exhibition space designs in the USM generate various reactions and new visitor responses during the visit. The museum which is basically an artifact display space, in the USM case, is no longer just displaying artifacts, but also functions as an 'artifact' itself that visitors can explore.

An exhibition design can influence visitors especially on the way visitors move and interact. The factor of visitor's comfort and freely movement can be one indicator to rate visitor satisfaction when visiting a museum. USM presents a new experience for visitors by inviting visitors not only to enjoy artifacts, but also to explore artifact display spaces as visiting concept with tour educator services. The mechanism and exhibition design of the USM supports new experiences for visitors to visit a museum.

\section{REFERENCES}

[1] Haryono, D., Museum Ullen Sentalu: Penerapan Museologi Baru

("Seminar towards Indonesian Postmodern Museums", 2011)

[2] Lefebvre, H., The Productions of Space. (Oxford: Blackwell, 1991)

[3] Tracy C. Davis, Performing and the Real Thing in the Postmodern Museum (The MIT Press, 1995), 2

[4] Soares, B., B., dan Maranda, L. (Ed.). The Predatory Museum. (Paris: ICOFOM Study Series. Vol. 45, 2017)

[5] Sirefman, S. 1999. Formed and Forming: Contemporary museum architecture. New York: The MIT Press. Daedalus, Vol. 128, No. 3, America's Museums. Pp. 297 320.

[6] Museum Ullen Sentalu, accessed on 26 Nov 2014 from www.ullensentalu.com 